\title{
Strengthening of tensile zone of the reinforced concrete beams with composite fabrics
}

\author{
Alla Volik $^{1^{*}}$, and Yan Novitski ${ }^{1}$ \\ ${ }^{1}$ Yanka Kupala State University of Grodno, 230023 Grodno, 22 Ozheshko str., Belarus
}

\begin{abstract}
A fabric, tapes, that are glued to the outer tensile surface, which are considered as the external composite reinforcement with tensile steel reinforcement, are currently used to strengthen reinforced concrete beams. The results of the experimental studies presented in this article have shown the possibilities of effective application of technical polyamide (nylon) fabric produced by «Khimvolokno Plant» JSC «Grodno Azot», and glass fabrics, produced by JSC «Polotsk-Steklovolokno» for strengthening the reinforced concrete beams. Experimental studies have shown that the external reinforcing of the tensile zone with technical polyamide (nylon) fabric and fiberglass changes the beam failure mode, increases the bearing capacity of reinforced concrete beams in comparison with beams without strengthening by $16 \%-38 \%$, depending on the material and the method of strengthening.
\end{abstract}

\section{Introduction}

Reinforced concrete structures occupy a leading place in the construction industry, and with the increase in the volume of construction, the volume of work associated with the repair, restoration and strengthening of structures also increases. The analysis of strengthening of reinforced concrete structures has shown that the traditional methods of strengthening associated with an increase in the cross-section dimensions, the arrangement of external elements, changes in structural schemes, etc. have exhausted themselves, since their further development will bring insignificant savings in materials. The results of modern research have shown [1-13] that it is possible to achieve greater savings in materials, reduce costs in the production of reinforcement work by using composite materials.

Currently, there are many different composite materials (Table 1), as well as ways to strengthen structures.

External reinforcement of beam structures is carried out by gluing reinforcing materials to the lower stretched surface with the direction of reinforcing fibers along the axis of the structure. Glued fabrics, tapes are external composite reinforcement, which, together with metal reinforcement, perceive stretched forces [15].

\footnotetext{
*Corresponding author: a.volick@grsu.by
} 
Table 1. Typical properties of composite materials fibers [14].

\begin{tabular}{|l|c|c|c|c|}
\hline Type of fiber & Tensile strength, MPa & $\begin{array}{c}\text { Modulus of } \\
\text { elasticity, GPA }\end{array}$ & $\begin{array}{c}\text { Relative elongation } \\
\text { strain, \% }\end{array}$ & Density, t/ $\mathbf{m}^{\mathbf{3}}$ \\
\hline Carbon Fiber & $4300-5100$ & $230-280$ & $1,6-1,73$ & 1,75 \\
\hline Carbon Fiber & $2740-5490$ & $294-329$ & $0,7-1,9$ & $1,78-1,81$ \\
\hline Carbon Fiber & $2600-4020$ & $390-760$ & $0,4-0,8$ & $1,85-1,90$ \\
\hline Aramid fibers & $3200-3600$ & $124-130$ & 2,4 & 1,44 \\
\hline Fiberglass & $2400-3500$ & $70-85$ & $3,5-4,7$ & 2,6 \\
\hline
\end{tabular}

The advantages of using external reinforcement that is made of composite materials are:

- low specific gravity of composite materials in relation to reinforced concrete, which simplifies installation,

- goint work of composite material (external reinforcement) and reinforced structure, which is ensured by a reliable adhesive connection;

- reinforcement elements, based on composite materials, resistant to corrosion and aggressive environments, which leads to increased durability and protection of the glued face from corrosion;

- the ability to work in cramped conditions;

- work can be carried out as soon as possible.

The most common for the restoration of reinforced concrete structures is currently a system of external reinforcement with carbon tapes. As a result of experimental studies [16 - 20], it was found that beams reinforced with carbon canvas work more elastically and have increased bearing capacity and rigidity. However, the introduction of this material is limited by the high cost.

\section{Experimental study}

The experimental studies of reinforced concrete beams reinforced from destruction by normal cross-section were carried out to determine the most effective method and material of strengthening reinforced concrete structures.

Two series of experimental beams with dimensions of $60 \times 120 \times 1000 \mathrm{~mm}$ were manufactured and tested to study the load-bearing capacity of bent elements strengthened with composite materials: beams of series I (B2, B3) were strengthened with fiberglass produced by JSC «Polotsk-Steklovolokno», beams of series II (B4, B5) were strengthened with technical polyamide (nylon) fabric produced by «Khimvolokno Plant» JSC «Grodno Azot». In each series, the beams had a different strengthening option: beams B2, B4 were reinforced with composite fabrics only on the lower surface, B3, B5 - with a U-shaped cage in the stretched zone.

A beam without reinforcement was tested (B1) to determine the effectiveness of reinforcement. The beam was reinforced with a welded frame made by spot welding. Longitudinal stretched rebar - metal rebar $\varnothing 10$ of class S500, compressed zone rebar $-\varnothing 6$ of class S240. The transverse reinforcement $\varnothing 10$ of class S240 is installed in increments of $50 \mathrm{~mm}$.

The beams were manufactured at the efficiency plant of JSC "Grodnozhilstroy" from concrete of class $\mathrm{C} 25 / 30$.

The tests were carried out with the application of concentrated forces at a distance of $1 / 3$ of the beam length from the supports (Fig. 1), since a constant bending moment acts in the zone between the concentrated forces, and there is no transverse force. In this zone, only normal stresses act, which makes it possible to assess the bearing capacity of the section without the influence of other factors. Experimental studies of the beams were carried out on an IP6084-1000-0 testing machine. 


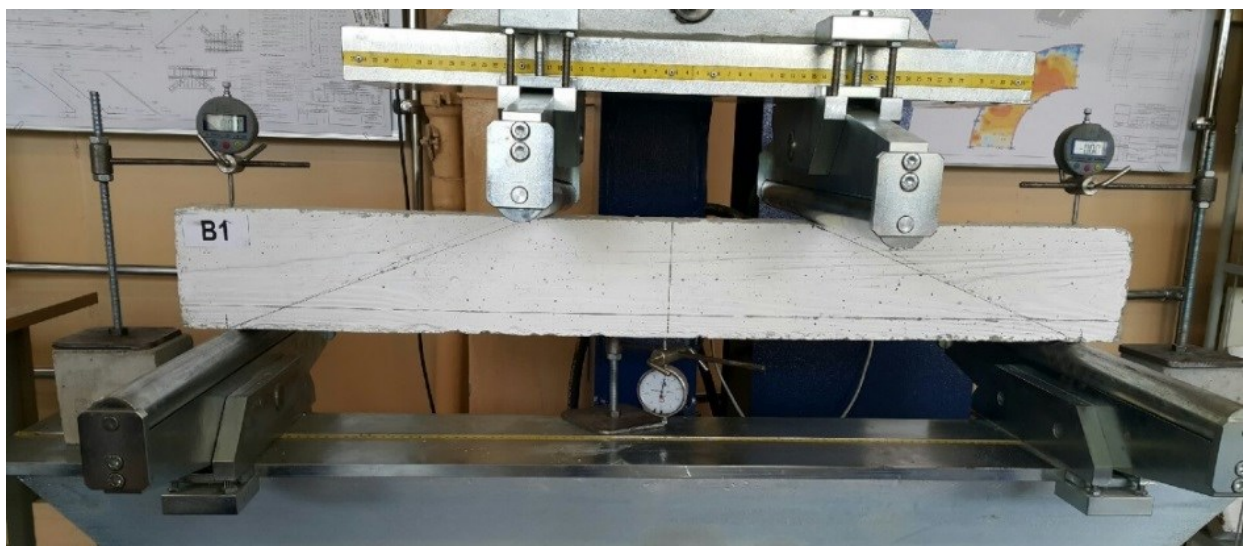

Fig. 1. Test bench for experimental beams.

Analysis of the destruction of the experimental beams showed that the destruction of the unreinforced beam occurred along the normal section in the clean zone as a result of plastic deformations in the tensile zone of the reinforcement at a load of $19.46 \mathrm{kN}$. The destruction of the reinforced beam B2 occurred along an inclined section at a load of $24.69 \mathrm{kN}$, beams $\mathrm{B} 3, \mathrm{~B} 4$ and $\mathrm{B} 5$ along normal sections due to crushing of concrete in the compressed zone, at a load of $26.2 \mathrm{kN} ; 22.57 \mathrm{kN} ; 26.91 \mathrm{kN}$, respectively (Fig. 2).
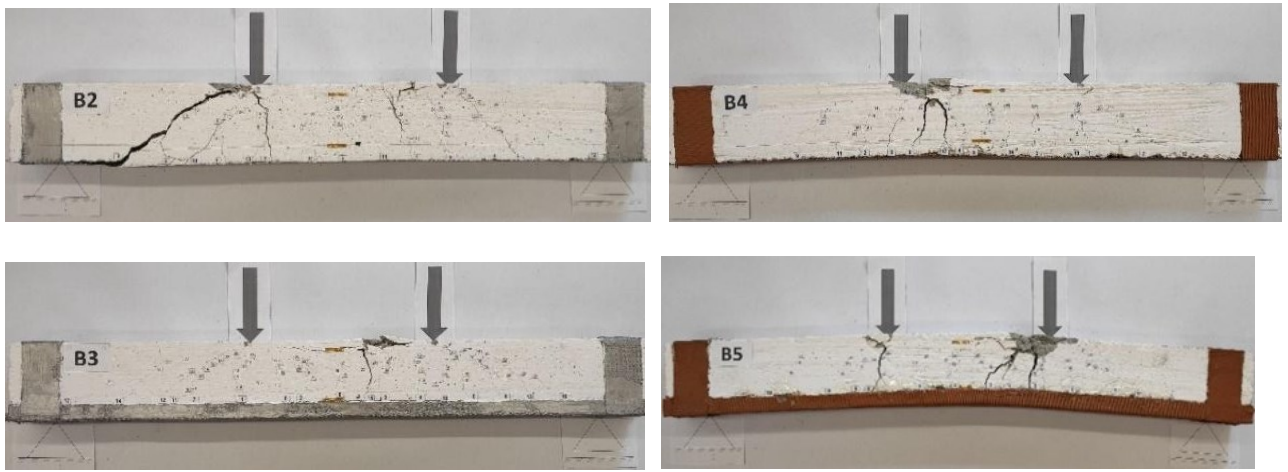

Fig. 2. The nature of the destruction of experimental reinforced beams.

It has been experimentally established that external strengthening changes the nature of the destruction and confirms the effectiveness of these amplification options regardless of the amplification option.

The analysis of the bearing capacity of the experimental beams showed (Figure 3):

- the maximum value of the breaking load was shown by beams, that were strengthened with a U-shaped cage in the tensioned zone (B3, B5); the increase in the breaking load was $34.63 \%$ when using fiberglass for reinforcement, and $-38 \%$ when using technical polyamide (nylon) fabric;

- an increase in the breaking load of beams, that were strengthened only along the lower edge, was $26 \%$ when using glass fabric reinforcement, and $-15 \%$ when using technical fabric reinforcement;

- beams with fiberglass reinforcement had a bearing capacity of $26.9 \%$ - $34.63 \%$ more than beams B1;

- beams with technical fabric reinforcement had a bearing capacity of $16 \%-38 \%$ more than beams B1. 


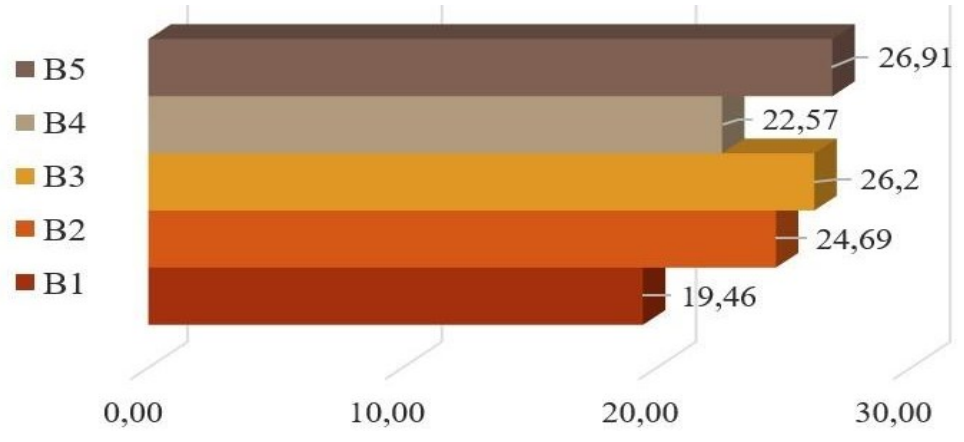

Fig. 3. - Bearing capacity of experimental beams

\section{Conclusion}

It is made a calculating estimate the conditions for ensuring the uniform strength of rupture and braid coils of construction composite reinforcement bar for shear and crushing. Theoretically substantiated the assumption of a relatively low loading capacity of the braid coils in comparison with the loading capacity of the reinforcement bar. The results obtained can be used by manufacturers and consumers of construction composite reinforcement, also in the educational process at the training of engineering personnel for the construction profile.

\section{References}

1. F.S. Vlasenko, A, E. Raskutin, Application of polymer composite materials in building structures, Proceedings of VIAM, 8, 3-6 (2013)

2. N.A. Fizdel, Defects in structures, structures and methods of their elimination (1987)

3. Yu.A. Nesterenko, Modern methods of strengthening reinforced concrete structures, Youth Scientific Forum: Technical and Mathematical Sciences 9(16), 4-7 (2014), http://www.nauchforum.ru/archive/MNF_tech/9(16).pdf

4. A.A. Shilin, V.A. Pshenichny, D.V. Kartuzov, External reinforcement of reinforced concrete structures with composite materials (2017)

5. D.A. Shevtsov, Strengthening of Reinforced Concrete Structures with Composite Materials, Industrial and Civil Engineering, 8, 61-65 (2014)

6. https://magazine.neftegaz.ru/articles/pererabotka/504745-kompozity-21-veka-vozmozhnosti-irealnost/

7. D.N. Smerdov, A.A. Nerovnykh, Technique for experimental studies of bending reinforced concrete elements reinforced with composite materials, Bulletin of the Siberian State University of Railways (Novosibirsk), 21, 146-155 (2008)

8. https://www.materialstoday.com/materials-chemistry/articles/s1369702115001601/

9. S.A. Bokarev, D.N. Smerdov, Experimental studies of flexible reinforced concrete elements reinforced with composite materials, Izvestiya Vuzov. Building, 2, 112-124 (2010)

10. A.A. Nerovnykh, Improving the efficiency of reinforcing bent reinforced concrete elements with composite materials, Science and Youth of the XXI Century, 83-84 (2010)

11. J.G.S. Alexander, J.J.R. Cheng, Field application and studies of using CFRP sheets to strength en concrete bridge girders, Advanced composite materials in bridges and structures: Canadian Society for Civil Engineering, Montreal, 465-472 (1996)

12. A.R. Volik, T.S. Novikova, A.A. Svintitsky, The strengthening of bending reinforced concrete elements using composite fabrics, Architectural and construction complex: problems, prospects, innovations, 128-131 (2018) 
13. A.R. Volik, E.K. Volik, K.Yu. Churilo, The strength of reinforced concrete beams reinforced with polyamide (nylon) fabric produced by PTC "Khimvolokno" JSC "GrodnoAzot", Trends and Prospects for the Development of Science of the XXI century (Syzran), 32-34 (2016)

14. D.V. Kurlapov, A.V. Rodionov, The strengthening of reinforced concrete structures using polymer composites, Engineering and Construction Journal, 3, 2-9 (2009)

15. Ahmad Mihub, P.P. Polskoy, D.F. Mayilyan, A.M. Blagoz, Comparison of experimental and theoretical strength of reinforced concrete beams reinforced with composite materials, using different calculation methods, New Technologies, 2-6, (2012)

16. E.S. Wagner, The strengthening of reinforced concrete structures with composite materials, Achievements of university science, 2-4 (2010)

17. S.V. Klyuev, Yu.V. Guryanov, External reinforcement of flexible fiber-concrete products with carbon fiber, Magazine of Civil Engineering, 1, 1-3 (2013)

18. A.R. Volik, Experimental studies of the strengthening of reinforced concrete beams using carbon, Promising directions for the innovative development of construction and training of engineering personnel, Part 1, 109-112 (2018)

19. Yu.G. Khayutin, V.L. Chernyavsky, E.Z. Axelrod, The use of carbon fiber reinforced plastics to strengthen building structures, Concrete and Reinforced Concrete, 1, 25-29 (2003)

20. S.V. Klyuev, R.V. Lesovik, Calculation of bending structures reinforced with composites based on carbon fiber, Bulletin of the Belgorod State Technological University named after V.G.Shukhov, 4, 55-58 (2011)

Information about authors:

1. Volik Alla - PH.D, Associate Professor, Dean of the Faculty of Engineering and

Construction of EE "Yanka Kupala State University of Grodno"

e-mail: a.volick@grsu.by

3. Yan Novitski - Senior Lecturer of the Department of Building Structures, "Yanka

Kupala State University of Grodno"

e-mail: novickij_yy@grsu.by 